\title{
Databases and Registries on Traumatic Spinal Cord Injury in Canada
}

Can J Neurol Sci. 2013; 40: 454-455

Reliable and accessible data are essential to determine the epidemiology of traumatic spinal cord injury. A registry or comprehensive database can also generate key information to ascertain the potential impact of healthcare management strategies and health policies that are focused on the prevention and reduction of the consequences of spinal cord injury. To date, some initiatives have supported the development and implementation of hospital-based, regional and national databases in Canada.

Information from hospital-based databases is of great value in the service planning, resource allocation and quality assessment of a particular institution or locality. Yet, institutional data have a limited usefulness for a broader analysis at the provincial and national levels given their limited generalizability. For instance, Pickett et al reported the epidemiology of traumatic spinal cord injury based on a retrospective analysis of the London Health Sciences Centre computerized medical records database of patients with spinal cord trauma ${ }^{1}$. Despite the importance of their contribution to the literature, the paper title, "Epidemiology of Traumatic Spinal Cord Injury in Canada", is obviously misleading.

Our recent study using data of patients with acute spine trauma from the Toronto Western Hospital Spinal Program Clinical Database underlines other important contributions of the hospital-based databases ${ }^{2}$. The comparison between the data from Toronto Western Hospital with the Ontario Trauma Registry revealed that our in-hospital mortality rate (4\%) was significantly lower than the provincial rate from the Ontario Trauma Registry (7.5\%), which reinforces the recommendations for early management of spinal cord injured patients in a spine trauma center ${ }^{3}$. When comparing data from Toronto Western Hospital with the National Trauma Registry, we found significant differences between the databases regarding the age distribution. These findings prompted the question whether the national figure of spinal cord injury is not consistent with data from spine trauma centers or a validation of the National Trauma Registry is necessary.

The National Trauma Registry is a pioneering initiative that has been collecting data on patients with trauma (including spine trauma) admitted in the participating hospitals across Canada since $2005^{4}$. Data collection for the National Trauma Registry is managed by the Canadian Institute for Health Information, which is a national, independent, non-profit organization that coordinates and publishes data related to health information system of Canada. This information is used to assess the health care system and assist influence public health policy to effectively manage health care systems of Canada, while also promoting issues of health among the general public. Each participating hospital, from most Canadian provinces, except Manitoba and Quebec, sends deidentified data on patients' hospitalizations to the Canadian Institute for Health Information, where all data are compiled and analyzed generating reports for the fiscal years (from May of one year to April of the subsequent year). Information on spine trauma has also been reported in prior studies that used data from the provincial sections of the National Trauma Registry including Alberta Trauma Registry ${ }^{5}$ and Ontario Trauma Registry ${ }^{2,6-9}$. The National Trauma Registry essentially provides data on age and sex distribution as well as injury characteristics (i.e. paraplegia versus tetraplegia).

A recent study scrutinised the National Trauma Registry with respect to its validation as either a spine trauma database or an spinal cord injury database ${ }^{10}$. The use of the National Trauma Registry as a spine trauma database had an accuracy of $87 \%$, sensitivity of $89.8 \%$ and specificity of $25 \%$. If the National Trauma Registry was considered as a spinal cord injury database, there would be a decrease in the precision with an accuracy of $32.6 \%$, sensitivity of $81.3 \%$ and specificity of $6.7 \%$. Injury characteristics (i.e. level and severity of spine trauma) and some codes of the International Classification of Diseases (Tenth revision) were significantly associated with false positive and negative results. Of note, miscoding is a common source of error in population-based registries. The performance of the National Trauma Registry as a spinal cord injury database was less satisfactory than when the National Trauma Registry is considered as a spine trauma database. As the National Trauma Registry showed relatively low specificity and negative predictive value in that single-institution validation study, a more comprehensive validation study using data from the other institutions would be recommended.

Another national spinal cord injury registry has been structured by the Translational Research Program of the Rick Hansen Institute since 2004 ${ }^{11}$. The Rick Hansen Spinal Cord Injury Registry is aimed to collect data on patients with acute traumatic spinal cord injury who are admitted to major trauma centers in 14 cities located in nine provinces. The current minimal data set includes data on age, sex, injury characteristics, neurological assessment and clinical procedures, but in a few sites, only age, sex and date of injury have been collected due to institutional ethical constraints. To date, the number of cases with completed data collection is still insufficient to draw a Canadian figure of traumatic spinal cord injury. Based on the experience from the Registry of the Canadian Stroke Network ${ }^{12}$, successful implementation and sustainability of this new national spinal cord injury registry will rely on overcoming important political, financial, ethical, legal and technical challenges. The latter includes the need for quality control of the collected data and proper validation using the data abstracted from an adequate sample of the patient charts as the gold standard.

In summary, the currently available population-based databases and registries on traumatic spinal cord injury in Canada offer limited data to researchers, hospital administrators, 
and policy makers in the management of patients and in the development of prevention strategies in the field of acute spine trauma. The National Trauma Registry and the Rick Hansen Spinal Cord Injury Registry are the potential population-based databases on spinal cord injury of almost national projection in Canada. While the former provides minimal data on spinal cord injury, the latter can potentially deliver more comprehensive data including neurological assessment and management details if that registry is successfully implemented in all intended sites. In either case, validation studies would be warranted to confirm their data accuracy.
Julio C. Furlan

Toronto Western Research Institute Toronto, Ontario, Canada Email:jcfurlan@gmail.com

\section{REFERENCES}

1. Pickett GE, Campos-Benitez M, Keller JL, Duggal N. Epidemiology of traumatic spinal cord injury in Canada. Spine (Phila Pa 1976). 2006 Apr 1;31(7):799-805.

2. Kattail D, Furlan JC, Fehlings MG. Epidemiology and clinical outcomes of acute spine trauma and spinal cord injury: experience from a specialized spine trauma center in Canada in comparison with a large national registry. J Trauma. 2009 Nov; 67(5):936-43.

3. PVA. Early acute management in adults with acute spinal cord injury: a clinical practice guideline for health-care professionals. Washington, DC: Paralyzed Veterans of America; 2008.

4. CIHI. National Trauma Registry 2003 Report. Canadian Institute for Health Information. 2003; Available from: www.chihi.ca.

5. Dryden DM, Saunders LD, Rowe BH, et al. The epidemiology of traumatic spinal cord injury in Alberta, Canada. Can J Neurol Sci. 2003 May;30(2):113-21.

6. Couris CM, Guilcher SJ, Munce SE, et al. Characteristics of adults with incident traumatic spinal cord injury in Ontario, Canada. Spinal Cord. 2010 Jan;48(1):39-44.

7. Jaglal SB, Munce SE, Guilcher SJ, et al. Health system factors associated with rehospitalizations after traumatic spinal cord injury: a population-based study. Spinal Cord. 2009 Aug;47(8): 604-9.

8. Munce SE, Guilcher SJ, Couris CM, et al. Physician utilization among adults with traumatic spinal cord injury in Ontario: a population-based study. Spinal Cord. 2009 Jun;47(6):470-6.

9. Munce SE, Wodchis WP, Guilcher SJ, et al. Direct costs of adult traumatic spinal cord injury in Ontario. Spinal Cord. 2013 Jan;51 (1):64-9.

10. Furlan JC, Fehlings MG. The National Trauma Registry as a Canadian spine trauma database: a validation study using an institutional clinical database. Neuroepidemiology. 2011;37(2): 96-101.

11. Noonan VK, Kwon BK, Soril L, et al. The Rick Hansen Spinal Cord Injury Registry (RHSCIR): a national patient-registry. Spinal Cord. 2012 Jan;50(1):22-7.

12. Silver FL, Kapral MK, Lindsay MP, Tu JV, Richards JA. International experience in stroke registries: lessons learned in establishing the Registry of the Canadian Stroke Network. Am J Prev Medicine. 2006 Dec;31(6 Suppl 2):S235-7. 